\title{
Optimizing interfacial features to regulate neural progenitor cells using polyelectrolyte multilayers and brain derived neurotrophic factor
}

\author{
Kun Zhou \\ Department of Materials Engineering and Monash Immunology and Stem Cell Laboratories, \\ Monash University, VIC 3800, Australia \\ Gui Zhi Sun \\ Monash Immunology and Stem Cell Laboratories, Monash University, VIC 3800, Australia \\ Claude C. Bernard and George A. Thouas \\ Department of Zoology, The University of Melbourne, VIC 3010, Australia \\ David R. Nisbet \\ ANU College of Engineering and Computer Science, The Australian National University, \\ ACT 0200, Australia \\ John S. Forsythe ${ }^{\text {a) }}$ \\ Department of Materials Engineering, Monash University, VIC 3800, Australia
}

(Received 13 August 2011; accepted 7 October 2011; published 26 October 2011)

\begin{abstract}
The development of biomaterials with controllable interfacial features which have the capability to instruct cellular behavior are required to produce functional scaffolds for the treatment of spinal cord injury (SCI). Here, poly-e-caprolactone surfaces were biofunctionalized via layer-by-layer (LbL) deposition. The polyelectrolytes employed in this LbL technique were heparin and poly-L-lysine (PLL), the latter being chosen to improve cell adhesion and the subsequent cellular function of in vitrocultured neural progenitor cells. Material characterization results confirmed the deposition of well structured multilayers. Cell culture studies revealed significant differences in the cellular response to these adhesive/nonadhesive (PLL/heparin) polyelectrolyte multilayer (PEM)surfaces, with neurite outgrowth being significantly promoted on the PLL terminating layers. In addition, brain derived neurotrophic factor (BDNF) was adsorbed onto the LbL surfaces. This combined chemical and biological effect was then characterized in terms of neurite length along with the full length/truncated isoform 1 tyrosine kinase receptor (TrkB-FL/TrkB-T1) and growth associated protein-43 mRNA levels. Here, the authors report the differential effect of adsorbed and soluble BDNF of different concentrations. Adsorbed BDNF promoted neurite outgrowth and led to elevated, sustained TrkB mRNA levels. These findings highlight the potential of PEM biofunctionalized surfaces with integrated chemical and neurotrophin supportive cues to overcome SCI inhibitory environments and to promote regeneration. (c) 2011 American Vacuum Society.
\end{abstract}

[DOI: $10.1116 / 1.3656249]$

\section{INTRODUCTION}

Due to the inhibitory physiological micro-environment associated with spinal cord injury $(\mathrm{SCI})^{1,2}$ and the restricted regenerative capacity of axons in the central nervous system, ${ }^{3}$ spontaneous regeneration is limited. Current research has shown improved functional recovery using stem/progenitor cell based therapies ${ }^{4,5}$ and tissue engineering scaffolds are now being exploited to accommodate the transplanted stem/ progenitor cells, which are capable of both self-renewal and differentiation into all relevant neural phenotypes at the lesion site to replace injured or lost cells. ${ }^{6-9}$ Scaffolds must be engineered to not only provide a supportive and favorable cellular micro-environment for transplanted stem cells, but to also include guidance cues for cell migration and neurite outgrowth from endogenous and exogenous cell sources..$^{10,11}$ However, many biodegradable scaffolds have a limited inter-

\footnotetext{
${ }^{a)}$ Electronic mail: john.forsythe@monash.edu.
}

action with cells, due to their high hydrophobicity and lack of bioactive groups, ${ }^{12}$ presenting the current challenge of biofunctionalizing scaffold surfaces to improve cellular interactions and to actively control biological responses, such as cell adhesion, ${ }^{13}$ proliferation, ${ }^{14}$ and differentiation. ${ }^{15}$

Layer-by-layer ( $\mathrm{LbL}$ ) deposition, where the process takes place in aqueous environments, has the advantage of being capable of uniformly biofunctionalizing complex 3D scaffolds with interconnected porosity. ${ }^{14,16}$ The technique involves the sequential deposition of oppositely charged polyelectrolytes to build up polyelectrolyte multilayers (PEMs) with control over film thickness, biofunctionality, and surface stiffness by changing polyelectrolyte pairs, $p \mathrm{H}$, ionic strength, and the concentration of the crosslinking agent. ${ }^{17-19}$ Entropy is the primary driving force for LbL deposition ${ }^{20}$ which relies on charge density matching and overcompensation of oppositely charged polyelectrolytes. ${ }^{21}$ Consequently, there is less restriction to the underlying substrate chemistry such as defects and trace contaminations, ${ }^{22}$ 
and moreover, numerous charged biomolecules including polysaccharides, ${ }^{13,23}$ polypeptides, and proteins ${ }^{24,25}$ can be used to produce surfaces tailored specifically for a variety of applications. Here, positively charged poly-L-lysine (PLL) which, at physiological conditions, is well known as a promoter of cell adhesion, ${ }^{26,27}$ and negatively charged heparin that has anti-inflammatory ${ }^{28,29}$ and anti-adhesive ${ }^{30}$ properties along with its specific binding of growth factors, ${ }^{31,32}$ were used. These deposited PEMs also provide abundant adsorption sites or reactive moieties for growth factor incorporation, ${ }^{23}$ such as brain-derived neurotrophic factor (BDNF) which we exploited in this study.

The BDNF binds with high affinity to the TrkB receptor, which is wildly expressed in the central nervous system and plays a crucial role in cell survival and neurite outgrowth for a variety of neuronal phenotypes. ${ }^{33,34}$ Truncated forms, which lack the tyrosine kinase component, along with the full length isoform of the TrkB receptor, can play an important role in neurogenesis in vivo. Following an SCI, regeneration is hindered due to the inhibitory environment and low levels of endogenous BDNF. ${ }^{35}$ Therefore, the delivery of exogenous BDNF to the injury site is of great importance. Traditional methods used to deliver BDNF (e.g., vein injection $^{36}$ and osmotic micropumps ${ }^{37}$ ) are limited due to the extremely short plasma half-life of BDNF $(0.92 \mathrm{~min})^{36}$ and the restricted long range interstitial diffusion in the central nervous system. ${ }^{38,39}$

Recent research has focused on various polyelectrolyte pairs interfaced with biological systems; however, most of the work involves the deposition of PEMs on silicon, gold, or glass substrates, and the use of tumor cells and/or fibroblasts as a model to study the cellular adhesion, proliferation, and cytotoxicity response. ${ }^{40}$ The aim of this study was to construct multilayers directly onto a poly- $\varepsilon$-caprolactone (PCL) film, a biomaterial that has been utilized both in vitro ${ }^{10}$ and in vivo ${ }^{41}$ for neural tissue engineering in the past. We investigated if optimizing the interfacial features using biofunctionalization could facilitate controlled cellular responses of neural progenitor cells (NPCs), which provides insight to the application of LbL biofunctionalzed scaffolds in vivo. To overcome the drawbacks of soluble neutrophins and to combine the chemical support (adhesive/spreading) with neurotrophic support, BDNF was physically adsorbed onto the PEMs, and NPC cultures were performed to study the combined cues and to compare adsorbed and soluble BDNF.

\section{MATERIALS AND METHODS}

\section{A. LbL deposition on PCL substrates}

A PCL (inherent viscosity $=1.00-1.30$, Absorbable Polymers, USA) was compression molded with a $25 \mathrm{kN}$ pressure at $80^{\circ} \mathrm{C}$ for $30 \mathrm{~s}$ to form a 2D film (average thickness $=0.34 \mathrm{~mm})$. These were then cut into $10 \times 10 \mathrm{~mm}^{2}$ substrates and washed in $50 \mathrm{v} / \mathrm{vol}$. \% ethanol/deionized water for $1 \mathrm{~min}$ in an ultrasonic bath. The surfaces of the substrates were activated by submersion in $20 \mathrm{mg} / \mathrm{mL}$ PEI (polyethyleneimine, molecular weight $=750000$, SigmaAldrich, St Louis, MO, USA) in phosphate-buffered saline (PBS) buffer $(p \mathrm{H}=7.4$, Sigma-Aldrich, St Louis, MO, USA) for $2 \mathrm{~h}$. A StratoSequence VI robot (nanoStrata Inc., USA) was used to carry out the automatic dip-rinse process. The LbL depositions on PEI activated substrates were conducted at $p \mathrm{H}=7.4$ in the PBS buffer. The substrates were then dipped into $5 \mathrm{mg} / \mathrm{mL}$ heparin (180 USP units/mg Sigma-Aldrich, St Louis, MO, USA) in the PBS buffer for $15 \mathrm{~min}$, followed by rinsing in the PBS buffer for $5 \mathrm{~min}$. They were treated the same way using $1 \mathrm{mg} / \mathrm{mL}$ PLL (molecular weight $=130000$ Sigma-Aldrich, St Louis, MO, USA) in the PBS ( $p \mathrm{H}=7.4)$ buffer. When the desired number of PEMs were deposited, the samples were collected for crosslinking or characterization. The PEMs are named by the type and number of the outermost polyelectrolytes (the terminating layer of the PEMs). For example, the first heparin deposition on PEI treated PCL (PCL/PEI/heparin) is denoted as H1, and the third PLL deposition (PCL/PEI/ heparin/PLL/heparin/PLL/heparin/PLL) is denoted as P3. The samples for the water contact angle and in vitro cell culture were crosslinked by immersion in 2 w/vol. \% N-(3dimethylaminopropyl)- $\mathrm{N}^{\prime}$-ethylcarbodiimide hydrochloride in the PBS for $2 \mathrm{~h}$, followed by thorough washing in deionized water.

\section{B. Quartz crystal microbalance with dissipation (QCM-D) monitoring of LbL deposition}

Gold coated quartz crystals were cleaned via UV-ozone treatment for $10 \mathrm{~min}$, followed by washing in piranha solution of $5: 1: 1$ (deionized water:ammonia: $\mathrm{H}_{2} \mathrm{O}_{2}$ ) and rinsed thoroughly in deionized water. The crystals were subsequently soaked in $5 \mathrm{mM}$ methyl 3-marcaptopropionate (Sigma-Aldrich, St Louis, MO, USA) in absolute ethanol (MERCK Pty. VIC, Australia) overnight to provide a superior surface for the subsequent coating of the PCL. The alkane-gold crystal was attached to a spin-coater (Laurell Technologies Corp.); a drop of $0.05 \mathrm{~g} / \mathrm{mL}$ PCL solution in tetrachloroethane (Sigma-Aldrich, St Louis, MO, USA) was placed on the center of the crystal, and then spun for $1 \mathrm{~min}$ at 6000 rpm to obtain a PCL thin film on the crystal. The PCL coated crystal was placed in a clean fume hood to allow residual solvent to evaporate, and then characterized by atomic force microscopy (AFM) and scanning electron microscopy (SEM, see the following text for details) to ensure full coverage without pin holes or large cracks prior to quartz crystal microbalance with dissipation (QCM-D) (Q-Sense E4, Sweden) analysis of the deposition process. This was performed by initially pumping the PBS buffer through the analysis chamber until the signal was stabilized. Each time the buffer or polyelectrolyte solution was pumped into the analysis chamber a single injection of $500 \mu \mathrm{L}$ over $54 \mathrm{~s}$ was employed. The measurements were taken continuously at the fundamental frequency $(5 \mathrm{MHz}), 3 \mathrm{rd}, 5 \mathrm{th}$, and 7 th overtones. The fundamental frequency was ignored since it was significantly affected by the crystal mounting. Data analysis and 
modeling were performed using QTools software provided by Q-Sense. For soft films, the film thickness was calculated by the viscoelastic model, since the Sauerbery model does not reflect the true values of viscoelastic coatings. ${ }^{42}$

\section{Water contact angle (CA) measurements}

Crosslinked PEMs were used for water contact angle (CA) measurements. Hydrophilicity of the PEMs was determined by $\mathrm{CA}$ analysis, using the standard sessile drop technique $^{43}$ on a video-based CA meter (Technical data OCA $20)$ at room temperature. A single water droplet was placed on the polymer surface by raising the vertically translating stage containing the substrate toward a water-filled glass syringe and capturing the droplet when a stable contact angle was obtained. The CAs were measured on CCD camera images using SCA202 software (Dataphysics, Germany). Measurements were performed at 6 random locations on PCL, PEI activated PCL, and H1 to H8 PEM surfaces, which had been pre-dried overnight in a vacuum oven.

\section{Atomic force microscopy (AFM) analysis}

The PCL coated QCM crystal surfaces and H8 surfaces built up on PCL coated QCM crystals were examined by AFM (Nanosurf Mobile S, Switzerland) in noncontact mode with a spring constant of $48 \mathrm{~N} / \mathrm{m}$. Three random areas of $50 \times 50 \mu \mathrm{m}^{2}$ size were scanned for each sample.

\section{E. BDNF adsorption}

Crosslinked P6 and $\mathrm{H} 7$ terminating PEM samples were chosen for BDNF adsorption and subsequent cell culture studies, since the coatings were found to be uniform after this number of layers. The samples were sterilized with $70 \%$ ethanol, and air dried in a laminar flow hood for $30 \mathrm{~min}$ before being soaked in PBS solutions containing 0.0001, $0.001,0.01,0.1,1$, and $10 \mu \mathrm{g} / \mathrm{mL}$ BDNF (Recombinant human BDNF, R\&D systems, Minneapolis, USA) at $4{ }^{\circ} \mathrm{C}$ overnight. The BDNF adsorbed samples were prepared in triplicate for ELISA and in vitro cell culture.

\section{F. Enzyme-linked immunosorbent assay (ELISA)}

The BDNF adsorbed PEMs were washed three times in 0.05 v/vol. \% Tween-20 (Sigma-Aldrich, St Louis, MO, USA) in PBS (PBS-T) for $10 \mathrm{~min}$, and were then blocked with $5 \mathrm{v} / \mathrm{vol}$. \% normal goat serum in the PBS-T (blocking buffer) for $40 \mathrm{~min}$. They were subsequently incubated with rabbit anti-BDNF diluted (1:750, Abcam, Cambridge, MA, USA) in blocking buffer at $37^{\circ} \mathrm{C}$ for $2 \mathrm{~h}$, before being washed in PBS-T for 10 min (4 times) and incubated with anti-rabbit IgG and HRP-linked antibody (Cell Signaling Technology, Danvers, MA, USA) and diluted in PBS-T $(1: 3000)$ at $37^{\circ} \mathrm{C}$ for $1 \mathrm{~h}$. They were again washed in the PBS-T for $10 \mathrm{~min}$ (four times) and transferred to a new 96well culture plate where they were mixed with stabilized peroxide and chromogen solution $\left(3,3^{\prime}, 5,5^{\prime}\right.$ - tetramethylbenzidine, R\&D systems, Minneapolis, MN, USA) for color development and incubated for $15 \mathrm{~min}$ at room temperature. The reaction was stopped by adding $1 \mathrm{M} \mathrm{HCl}$ into each well and the supernatant was analyzed using a plate reader (Benchmark Plus, Bio-RAD, NSW, Australia) at an absorbance wavelength of $452 \mathrm{~nm}$. Additional BDNF free and adsorbed PEMs were prepared for ELISA, with the latter using PBS instead of rabbit anti-BDNF antibody to serve as negative controls for background subtraction.

To test for desorption of BDNF into solution, BDNF adsorbed PEMs (the three highest concentrations used for in vitro culture $(0.1,1$, and $10 \mu \mathrm{g} / \mathrm{mL})$ were incubated in triplicate in $50 \mu \mathrm{L}$ of sterile PBS at $37^{\circ} \mathrm{C}$ for 6 days. The supernatant was collected every $24 \mathrm{~h}$ and replaced with fresh sterile PBS. Any desorbed BDNF was allowed to adhere to a Maxisorp plate (Nunc-Immuno, Thermo Fisher Scientific, VIC, Australia) at $4{ }^{\circ} \mathrm{C}$ overnight, then quantified by ELISA as previously described.

\section{G. Cell culture}

All cell culture reagents used were purchased from Invitrogen, Mulgrave, Australia, unless specified. Mouse embryonic stem cells (ES, W9.5) were cultured in Dulbecco's modified Eagle's medium (high glucose), supplemented with $15 \mathrm{v} / \mathrm{vol}$. \% fetal bovine serum (FBS), $1 \mathrm{v} / \mathrm{vol} . \%$ nonessential amino acid solution, 50 unit $/ \mathrm{mL}$ penicillin, $50 \mu \mathrm{g} / \mathrm{mL}$ streptomycin, $50 \mathrm{mM} 2 \beta$-mercapoethanol and $10^{3}$ unit $/ \mathrm{mL}$ leukemia inhibitory factor (Millipore, NSW, Australia). The ES cells were seeded at a density of $5 \times 10^{4}$ cells $/ \mathrm{cm}^{2}$ on mitomycin treated mouse embryonic fibroblasts (MEF, derived from 129 mouse) prepared earlier on gelatin-coated culture plates using the same seeding density, with sub-culturing every third day. ES/MEF co-cultures were collected, resuspended, and then incubated in Iscove's modified Dulbecco's medium (IMDM) with $10 \mathrm{v} / \mathrm{vol}$. \% FBS for $40 \mathrm{~min}$ to deplete the MEFs, since MEFs adhered to the culture plate earlier than the ES. Purified ES cells were then re-suspended at a density of $5 \times 10^{3}$ cells $/ \mathrm{mL}$ in a chemically defined medium composed of $49 \mathrm{v} / \mathrm{vol}$. \% IMDM, 49 v/vol. \% F12 nutrient mix, $1 \mathrm{v} / \mathrm{vol}$. \% chemically defined lipid concentrate, 1 $\mathrm{v} / \mathrm{vol} . \%$ insulin-transferrin-selenium-X, $0.5 \mathrm{w} / \mathrm{vol} . \%$ bovine serum albumin (BSA, Sigma-Aldrich, St Louis, MO, USA), $0.04 \mu \mathrm{L} / \mathrm{mL} \alpha$-monothioglycerol (MTG, Sigma-Aldrich, St Louis, MO, USA), $2 \mathrm{mM}$ L-glutamin, 25 unit $/ \mathrm{mL}$ penicillin, $25 \mu \mathrm{g} / \mathrm{mL}$ streptomycin, and $10 \mathrm{ng} / \mathrm{mL}$ bFGF, in nonadherent 96-well plates (Corning Inc., MA, USA) and allowed to expand to form larger embryoid bodies (EBs) over a 7 day period. After EB formation, neural inductive stimulation using bFGF led to a high fraction of NPCs. The aggregated EBs were then mechanically dissociated and the NPCs were seeded $\left(1 \times 10^{5}\right.$ cells $\left./ \mathrm{cm}^{2}\right)$ onto the PEM substrates and cultured in Supplement-free Neuronbasal A medium supplemented with $2 \mathrm{mM}$ L-glutamine, 50 unit $/ \mathrm{mL}$ penicillin, $50 \mu \mathrm{g} / \mathrm{mL}$ streptomycin, $1 \mathrm{v} / \mathrm{vol}$. \% insulin-transferrin-selenium-general, $1 \mathrm{v} / \mathrm{vol}$. \% N-2 supplement and $1 \mathrm{v} / \mathrm{vol}$. \% B27 serum-free supplement for 5 days without medium change. 
Culture groups included positive controls (PLL coated coverslips); negative controls (unmodified PCL); test groups that included all PEMs from $\mathrm{P} 4$ to $\mathrm{H} 8$ without BDNF, as well as P6, H7 PEMs with adsorbed/soluble BDNF; and corresponding biological controls (adsorbed BDNF with its bioactivity inhibited by sheep anti-BDNF antibody, Millipore, NSW, Australia). The PLL positive controls were prepared by incubating coverslips in $10 \mu \mathrm{g} / \mathrm{mL}$ PLL for $1 \mathrm{~h}$ before rinsing with MilliQ water prior to seeding. The PEM substrates without BDNF were sterilized by $70 \%$ ethanol, followed by air-drying for $30 \mathrm{~min}$ in a laminar flow hood. The preadsorbed BDNF (P6 and H7 layers) were washed in sterile PBS for $10 \mathrm{~min}$ (three times) prior to culture. The BDNF bioactivity inhibition was achieved by subjecting the cell suspension to sheep anti-BDNF antibody $(5 \mu \mathrm{g} / \mathrm{mL})$ which was then seeded onto the PEM substrates. ${ }^{44}$ As a control, soluble BDNF was also added into the media of the P6 and $\mathrm{H} 7$ layers prior to seeding at concentrations of 10 and $50 \mathrm{ng} / \mathrm{mL}$, respectively. All in vitro culture groups are summarized in Table I.

\section{H. Immunocytochemistry}

The PEMs and control groups were immunolabeled for neuronal markers after 5 days culture. Samples were fixed in $4 \mathrm{w} / \mathrm{vol}$. \% paraformaldehyde for $10 \mathrm{~min}$, washed in PBS, permeabilized in $0.2 \mathrm{v} / \mathrm{vol}$. \% Triton-X100 (Sigma-Aldrich, St Louis, MO, USA) for $5 \mathrm{~min}$ before additional washing in PBS. The samples were then quenched in freshly prepared $0.1 \mathrm{w} /$ vol. \% sodium borohydride (Sigma-Aldrich, St Louis, MO, USA) in PBS for 5 min before subsequent washes. Nonspecific antibody binding was prevented by blocking all samples with $3 \mathrm{v} / \mathrm{vol}$. \% normal goat serum (Vector Laboratories Ltd. UK) for $3 \mathrm{~h}$, followed by PBS washing. Samples were then incubated at $4{ }^{\circ} \mathrm{C}$ overnight in the following primary antibody solutions (dilution was $1 \mathrm{w} / \mathrm{vol}$. \% BSA/ PBS), mouse-anti- $\beta$ III-Tubulin (1:800) for neuronal lineages and rabbit-anti-GFAP $(1: 1000$, DAKO) for astrocytes. In addition, rabbit-IgG (1:1000) was used to stain PLL coated glass coverslips as a negative control, instead of the primary antibody (rabbit-anti-GFAP), to eliminate false positive staining unique to this particular antibody. Secondary antibodies, anti-mouse Alexa Flour 568 (1:1000) for neurons and anti-rabbit Alexa Flour 488 (1:1000) for astrocytes, were then incubated simultaneously on all samples for $1 \mathrm{~h}$, before washing 3 times in PBS and being counterstained with
TABLE II. Designed primers for RT-PCR study.

\begin{tabular}{|c|c|}
\hline Gene & Primer sequence $\left(5^{\prime}-3^{\prime}\right)$ \\
\hline TrkB-T1 & $\begin{array}{l}\text { forward: TGGTGATGTTGCTCCTGCTCAAGT } \\
\text { reverse: CCCATCCAGTGGGATCTTATGAAAC }\end{array}$ \\
\hline TrkB-FL & $\begin{array}{l}\text { forward: ACTTTGGCATCACCAACAGTCAGC } \\
\text { reverse: AGGTTGTAGCACTCGGCAAGGAAA }\end{array}$ \\
\hline GAP-43 & $\begin{array}{l}\text { forward: TGGTGTCAAGCCGGAAGATAA } \\
\text { reverse: GCTGGTGCATCACCCTTCT }\end{array}$ \\
\hline Housekeeping gene: & forward: TGTTCCTACCCCCAATGTGT \\
\hline $\begin{array}{l}\text { Glyceraldehyde- } \\
\text { 3-phosphate }\end{array}$ & reverse: CCCTGTTGCTGTAGCCGTAT \\
\hline Dehydrogenase (GAF & \\
\hline
\end{tabular}

4', 6-diamidino-2-phenylindole (DAPI) nuclear stain $(1: 10,000)$ for $20 \mathrm{~min}$.

\section{RNA preparation and real-time polymerase chain reaction (RT-PCR)}

Cells after 5 days of culture on the PEM surfaces with/ without BDNF were collected through subjection to 0.25 w/vol. \% trypsin, followed by centrifugation at $80 \mathrm{~g}$ before being re-suspended in $200 \mu \mathrm{L}$ of PBS. Following this, total RNA was extracted from the cells using a high pure RNA isolation kit following the manufacturer's protocol (Roche, NSW, Australia). A total of $1.5 \mu \mathrm{g}$ of RNA from each culture group was reverse transcribed to cDNA in a thermal cycler (MyCycler, Bio-RAD, NSW, Australia) using the SuperScript III First-Strand Synthesis System. Primer pairs (GeneWorks, SA, Australia) used in the real-time polymerase chain reaction (RT-PCR) study are listed in Table II.

Sybr green mixtures (Invitrogen, Mulgrave, Australia) were used for real-time PCR reactions. The amplification program started with preheating at $95^{\circ} \mathrm{C}$ for $2 \mathrm{~min}$, prior to 40 cycles of $95^{\circ} \mathrm{C}$ for $15 \mathrm{sec}, 54.6^{\circ} \mathrm{C}$ for $15 \mathrm{sec}$, and $68^{\circ} \mathrm{C}$ for $20 \mathrm{sec}$, which was preceded by running a melting curve analysis. The RT-PCR products were mixed with a loading buffer (5:1), and separated by agarose gel electrophoresis (2 w/vol. \% agarose gel with $0.005 \%$ ethidium bromide) to further confirm the single and specific amplification product that was measured by RT-PCR for each primer pair. The mRNA fold increase was calculated using the $2^{-\Delta \Delta \mathrm{Ct}}$ method. The PCR efficiencies were determined by a series of tenfold dilution templates, where standard curves showed

TABLE I. Control and PEM test groups for in vitro culture.

\begin{tabular}{|c|c|c|c|c|c|}
\hline \multicolumn{3}{|c|}{ Without BDNF } & \multicolumn{3}{|c|}{ With BDNF } \\
\hline Control & & & Test & Form of BDNF & BDNF concentration/density \\
\hline \multirow{4}{*}{$\begin{array}{l}\text { PLL coated coverslip; } \\
\text { Unmodified PCL }\end{array}$} & $\mathrm{P} 4$ & P5 & P6 & Soluble & 10 \\
\hline & P6 & P7 & & $(\mathrm{ng} / \mathrm{mL})$ & 50 \\
\hline & $\mathrm{H} 5$ & H6 & $\mathrm{H} 7$ & Adsorbed $^{\mathrm{a}}\left(\mathrm{nm} / \mathrm{cm}^{2}\right)$ & 1.29 \\
\hline & $\mathrm{H} 7$ & $\mathrm{H} 8$ & & & 2.81 \\
\hline
\end{tabular}

${ }^{\mathrm{a}}$ Values determined by ELISA. 
efficiencies of between 100-110\%, which meet the assumption for the $2^{-\Delta \Delta \mathrm{Ct}}$ method.

\section{J. Fluorescence imaging and quantitative analysis of cultured NPCs}

The PCL substrates where PEMs had been deposited and coverslips with adsorbed PLL were imaged using a fluorescence microscope (Provis, Olympus, Japan) and AnalysisProfessional software (Olympus Soft Imaging, Japan) for capturing images. The entire culture area of the scaffolds and coverslips was also mapped sequentially using a scanning epifluoresence microscope (XL20 Dotslide, Olympus, Japan) for subsequent quantitative analysis. Fluorescence levels and pixel counting were performed using Image-J software (National Institutes of Health, USA). To obtain random sampling, the entire culture surface image was divided into a 64-grid; then a random coordinate was generated by computer to choose the grid to be analyzed $\left(1.3 \times 0.8 \mathrm{~mm}^{2}\right)$ each time. Quantification of neurite density per area was estimated by counting the number of pixels occupied by $\beta$ III-tubulin positive staining based on a previous protocol, ${ }^{45}$ with DAPI positive staining to exclude the cell cluster regions. The DAPI positive pixels were also used to minimize the cell body area ( $\beta$ III-tubulin positive) in the noncell cluster regions for the calculation of the neurite density; however, the random sampling and sufficient sample numbers $(n=15)$ avoided a bias in the quantification due to random cell distribution (cell density) on the scaffolds. Threshold levels of intensity were constant and used to determine the optimal resting image in a sample of five random fields. The density of neurites was then expressed as percentage coverage by the relationship,

$$
\text { Neurite density }=\frac{\operatorname{pixels}(\beta \text { III }- \text { Tubulin positive stain })-\operatorname{pixels}(\text { DAPI positive stain })}{\text { Total pixels of the chosen field }} .
$$

The neurite length was measured on these randomly selected fluorescence images with an ImageJ plugin - NeuronJ. ${ }^{46}$ The tracing and quantification was performed on all visually distinguishable neurites of selected analysis areas $(n=50)$. The mean values of neurite coverage per unit area (percent) of scaffolds and the mean values of neurite length were determined.

\section{K. Statistics}

The neurite density comparisons on different PEM surfaces without BDNF were made between test groups, and the neurite length on the PEMs with/without adsorbed/soluble BDNF was compared between all culture groups using the Kruskal-Wallis test with Dunn's multiple comparisons test. For RT-PCR statistics analysis, all BDNF (adsorbed/soluble) treated groups were compared to the untreated group (no BDNF) with an unpaired t-test with Welch correction. The mRNA fold increase was also compared between adsorbed BDNF groups and soluble groups using a one-way analysis of variance (ANOVA) with Tukey post-test. All statistical analyses were performed using GraphPad Instat software (GraphPad Software, Inc.); p-values of less than 0.05 were considered to be significantly different.

\section{RESULTS}

During the entire LbL deposition process a decrease in the frequency change $(\Delta \mathrm{f} / \nu$, where $\nu$ is the overtone number) was observed using QCM analysis. This qualitatively indicated mass deposition and was observed upon each heparin injection, followed by a slight increase of $\Delta \mathrm{f} / \nu$ during PBS washes, which plateaus after $5 \mathrm{~min}$ (Fig. 1). By contrast, the initial PLL deposition (P1 and P2) only caused a slight drop of $\Delta \mathrm{f} / \nu$, which then increased after the P3 deposition. However, during PBS washes for the PLL electrolyte, the $\Delta \mathrm{f} / \nu$ changes were negligible throughout the LbL deposition.

The polyelectrolyte mass deposition is more clearly shown in the inset of Fig. 1. Both heparin and PLL deposition contributed to the mass increase during the LbL process. An exponential growth of heparin/PLL deposition was observed for all three overtones (the 3rd, 5th, and 7th), and $-\Delta \mathrm{f} / \nu$ showed a frequency dependence on thicker PEMs.

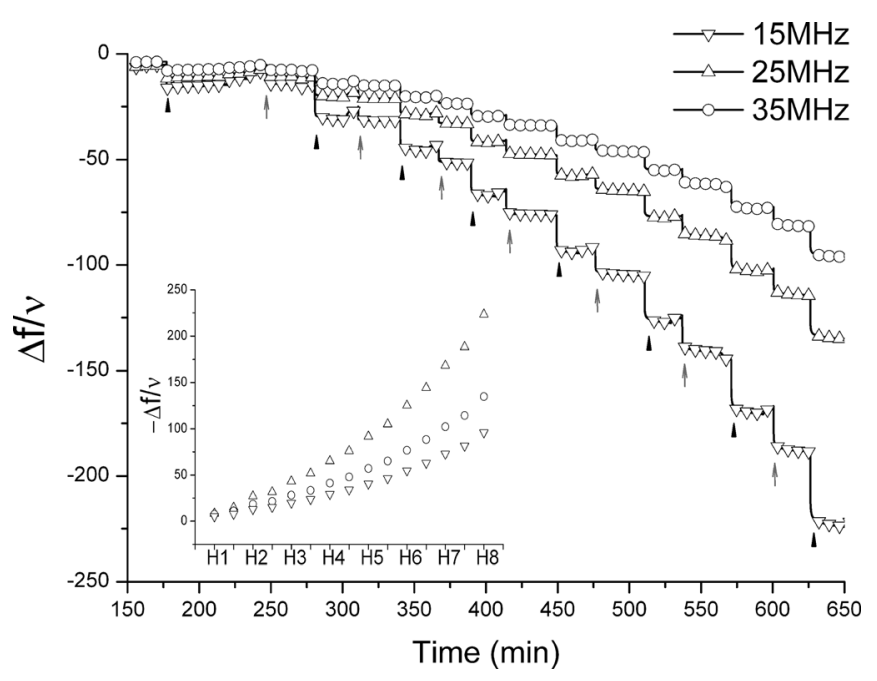

FIG. 1. QCM-D frequency shift $(\Delta \mathrm{f} / \nu)$ during LbL deposition; data points were collected after PBS signal stabilization, with the plot starting from the PBS wash after PEI activation prior to the PEM deposition. Black arrows indicate the injection of heparin; gray arrows indicate the injection of PLL. PBS washes after each deposition step are not indicated in the plot. Note: To aid clarity, only every 600 points were used from the entire data set to produce this plot. The inset shows the frequency difference $(-\Delta \mathrm{f} / \nu)$ after PBS washes of each polyelectrolyte deposition. 


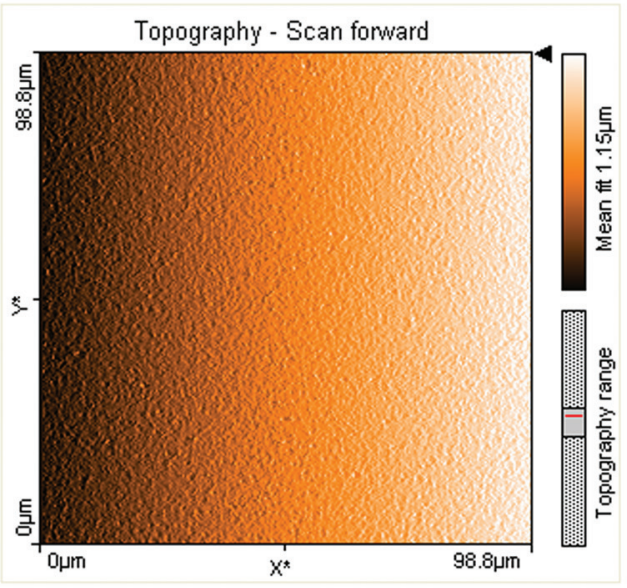

(A)

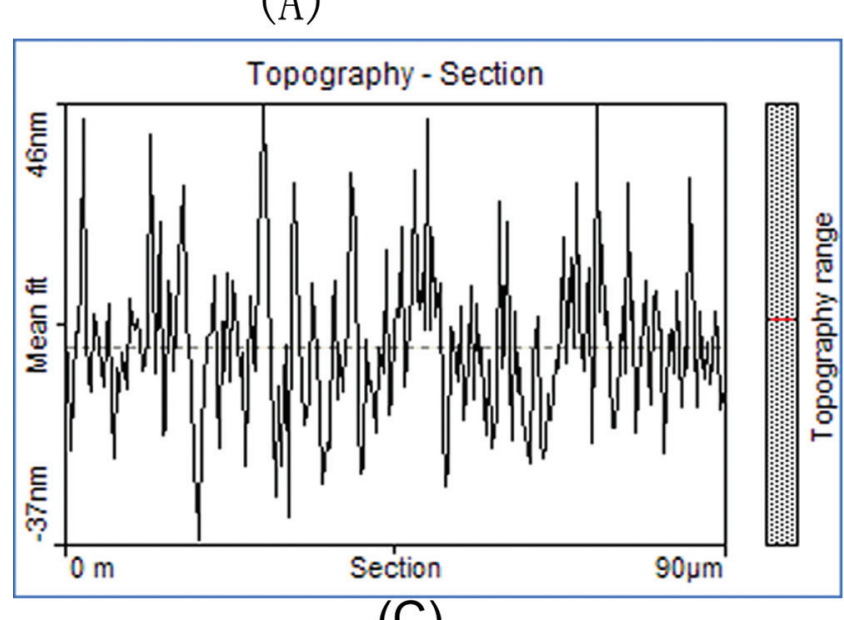

(C)

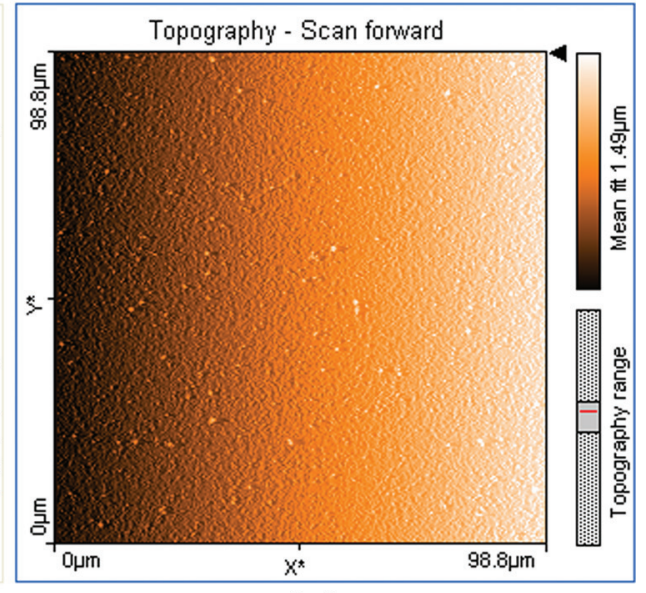

(B)

FIG. 2. (Color) AFM images of (a) a PCL coated QCM sensor crystal, (b) the H8 PEM surface on the PCL coated QCM sensor crystal, and (c) the line profile across the H8 AFM image.

The total PEM thickness was estimated to be $125 \mathrm{~nm}$ using the viscoelastic model, which assumes that each layer covers the entirety of the sensor and has a uniform thickness with homogenous structure. ${ }^{47}$

The SEM analysis of the PCL coated alkyl-Au showed a smooth surface (image not shown due to lack of topological contrast). After the deposition of the H8 layer, the PEM surface was discovered by AFM to be smooth, with only nanometer-sized surface roughness observed. Line profiles across the AFM images were also studied and the results showed no obvious morphology change between layers [Figs. 2(b) and 2(c)].

The wettability of unmodified PCL, PEI activated PCL, and PEMs (H1-H8) was characterized by CA measurements. The CA value dropped from $79^{\circ}$ to $71^{\circ}$ after PEI activation (Fig. 3). Subsequent deposition on the PEI activated PCL led to a regular alternating step change in the $\mathrm{CA}$ values, where heparin surfaces generally showed lower CA values compared to PLL surfaces.

Using our cell culture method, which was adapted from a previous protocol, ${ }^{49}$ neural progenitor cells were induced to differentiate preferentially into neurons. This was confirmed by our initial culture experiments, which showed the major- ity of the cells to be neurons ( $\beta$ III-Tubulin positive), a small number of astrocytes (GFAP positive), and no oligdendrocytes (NG2 positive). Therefore, in subsequent cultures, only $\beta$ III-Tubulin and DAPI staining was performed. Neuronal

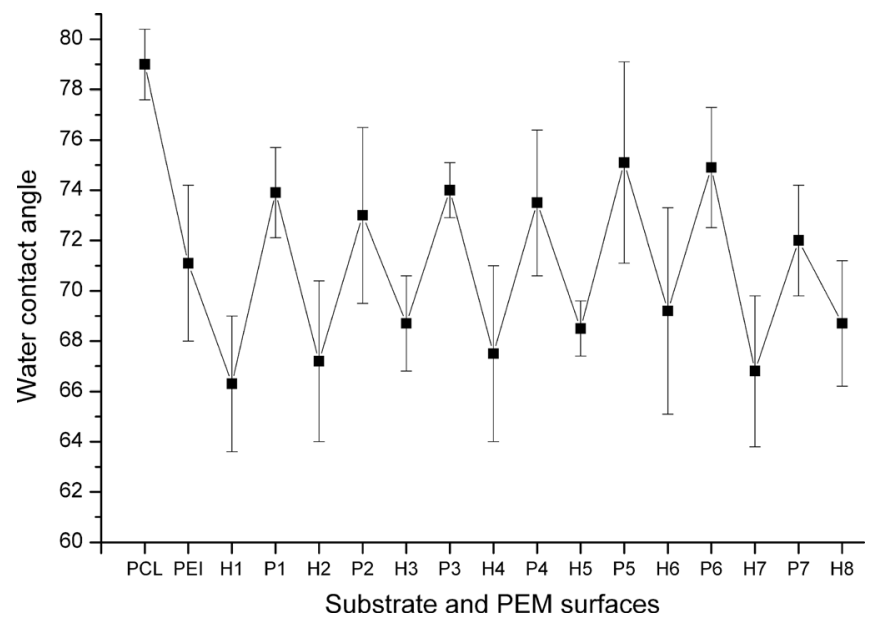

FIG. 3. Water contact angle measurements on PCL, PEI activated PCL, and PEM surfaces from $\mathrm{H} 1$ to H8. Error bars show standard deviation; sample size, $\mathrm{n}=6$. 

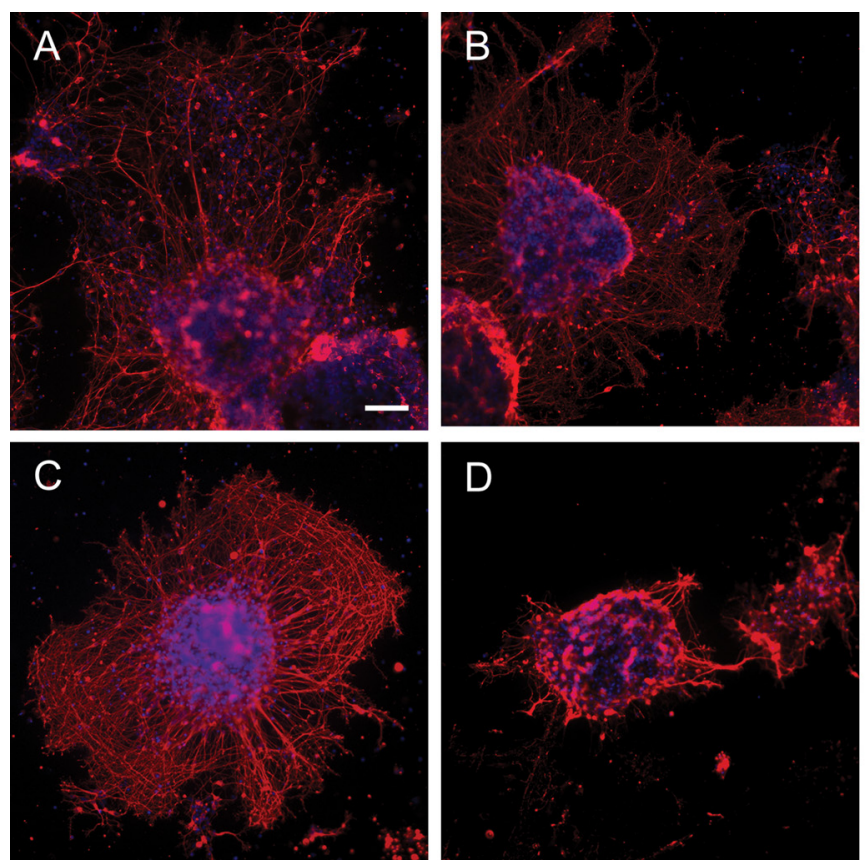

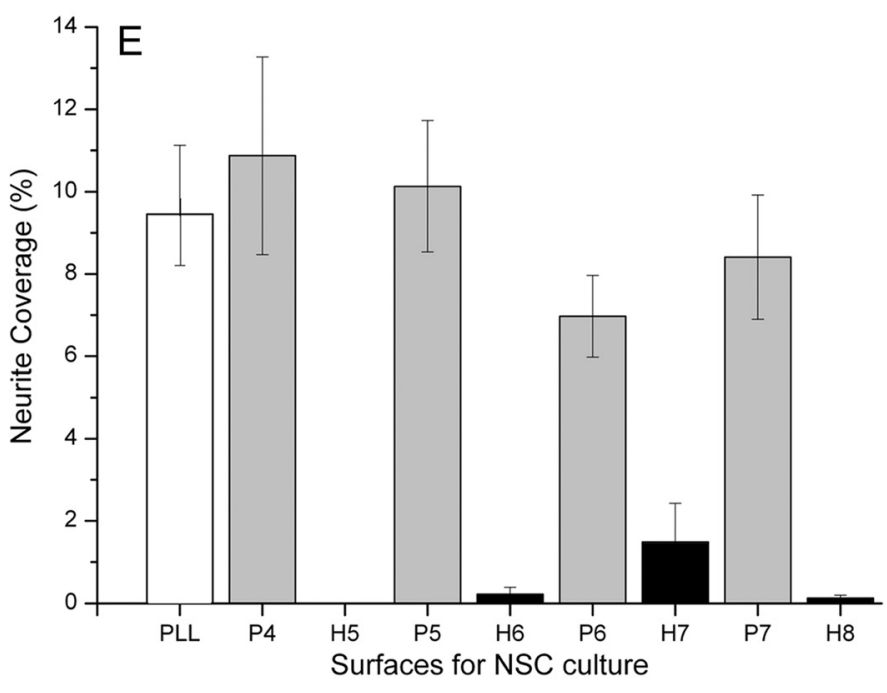

FIG. 4. (Color online) (a) Cells cultured for 5 days on the PLL positive control, (b) P4, (c) P5, and (d) H6 PEM surfaces. The cells were stained by $\beta$ III-Tubulin (red) for neurons and DAPI (blue) for nuclei. Scale bars indicate $100 \mu \mathrm{m}$ in (a)-(d). (e) Day 5 neurite coverage (from cell clusters) on the PLL positive control, the PEMs from P4 to H8 in the absence of BDNF; error bars show standard deviation of the mean. Sample size, $\mathrm{n}=15$. Unmodified PCL culture groups were not included in the neurite coverage plot. A significant difference $(\mathrm{p}<0.001)$ was observed between the PLL and heparin terminating layers.

spreading was observed on both PLL positive controls and PLL terminating PEMs, with neurites radially elongating, and, in some cases, perpendicular side branching at the periphery of outgrowths was present [Fig. 4(c)]. The PLL terminating PEMs [Figs. 4(b) and 4(c)] had a similar density of neurites compared to the PLL positive control [Fig. 4(a)]. In contrast, few cells were found on the unmodified PCL (data not shown). Similarly, for heparin terminating surfaces, while some cell colonies were seen to adhere, neurite elongations were relatively short and sparse [Fig. 4(d)]. Based on the quantified neurite coverage [Fig. 4(e)], cell-substrate interactions were significantly improved on the PLL terminating surfaces in terms of neurite coverage. Heparin terminating PEM surfaces showed significantly lower $(p<0.001)$ neurite coverage than the positive control and surfaces terminating in PLL.

The BDNF was adsorbed on the $\mathrm{P} 6$ and $\mathrm{H} 7$ terminating layers, with ELISA showing a linear correlation between the amount of BDNF in solution (up to $10 \mu \mathrm{g} / \mathrm{mL}$ ) and that adsorbed on the different terminating layers (Fig. 5). To test the possibility of BDNF desorption, the three highest BDNF concentrations used for subsequent in vitro cultures $(0.1,1$, and $10 \mu \mathrm{g} / \mathrm{mL}$ ) were incubated in sterile PBS for 6 days. Analysis of the supernatant during this period by ELISA did not detect the presence of soluble BDNF.

Following BDNF adsorption to $\mathrm{P} 6$ and $\mathrm{H} 7$ terminating PEMs, enhanced effects on neuronal differentiation from NPCs were observed. Figure 6 shows the immunostaining on P6 surfaces with/without adsorbed or soluble BDNF of different concentrations. However, longer neurites were observed on adsorbed BDNF surfaces, which was concentra- tion dependent. The dosage effect (BDNF) was more pronounced when the growth factor was adsorbed on the PEMs, even at the lowest surface density $\left(0.65 \mathrm{ng} / \mathrm{cm}^{2}\right)$. However, when adsorbed BDNF was blocked using a BDNF antibody that was added in the culture media, neurite length dropped back to a level similar to the groups that were not subjected to BDNF. [High resolution images chosen from Fig. 6 are shown in the Appendix (Fig. 9).]

Neurites on the P6 surface without BDNF stimulation had an average length of $50 \mu \mathrm{m}$ (Fig. 7). Both adsorbed and soluble BDNF significantly promoted neurite elongation in a

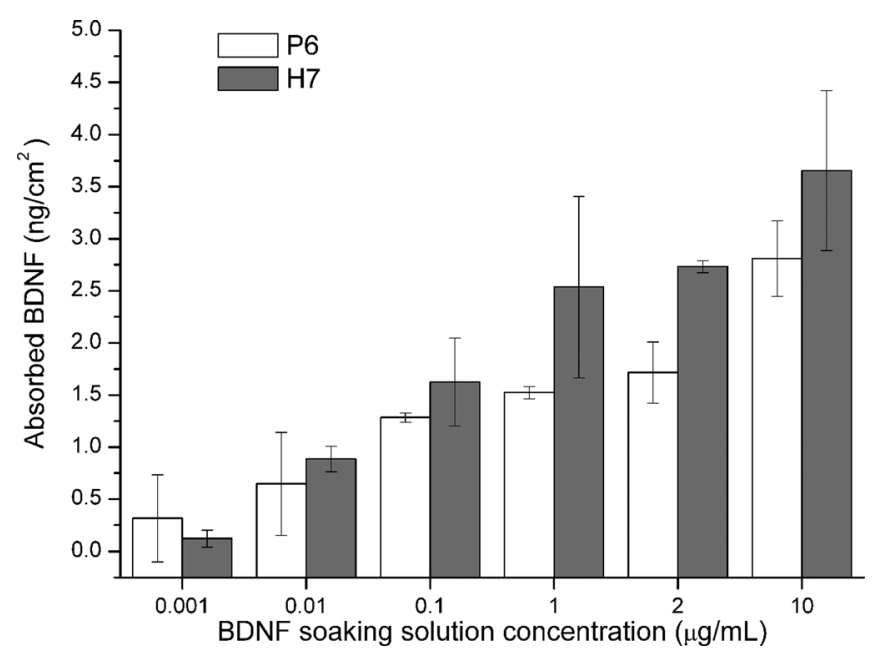

FIG. 5. Amount of BDNF adsorbed on the P6 and $\mathrm{H} 7$ surfaces with each sample being performed in triplicate and quantified by ELISA. Error bars are shown as standard deviations. 

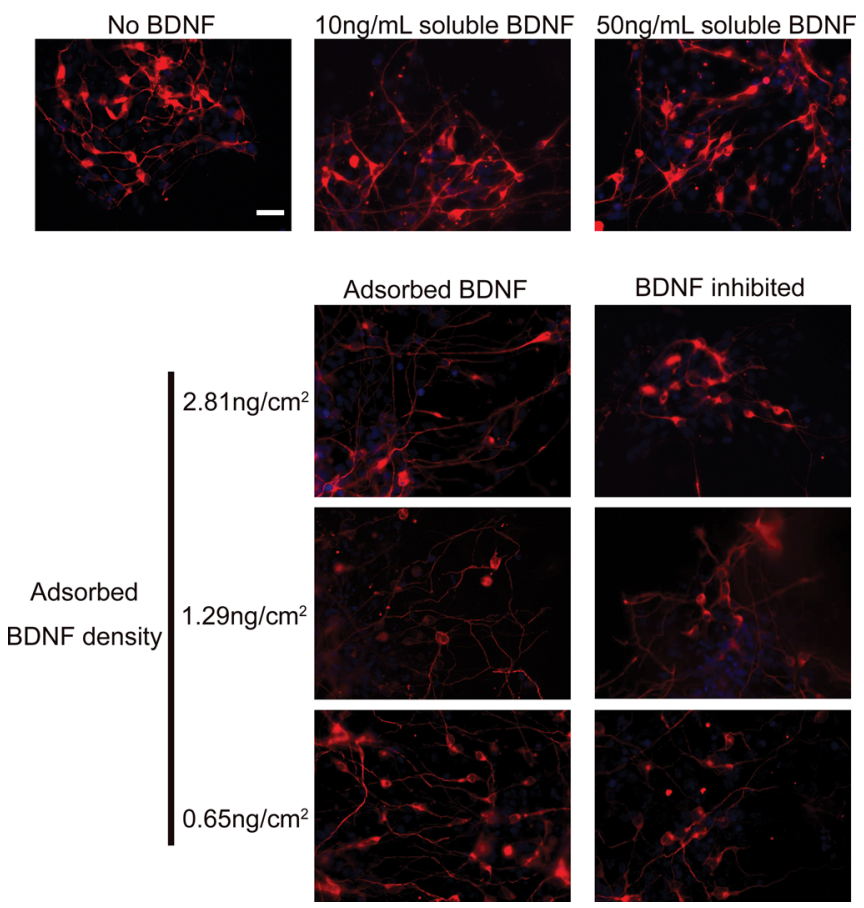

BDNF inhibited
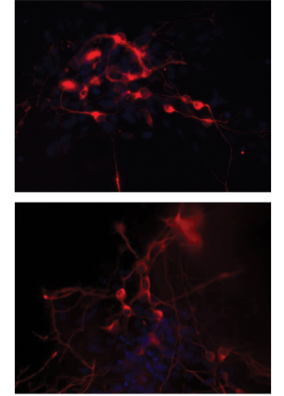

FIG. 6. (Color online) NPCs cultured on P6 surfaces with adsorbed/soluble BDNF of different concentrations and corresponding BDNF inhibited groups (5 days of culture). Cells were marked with $\beta$ III-Tubulin (red) for neurons and DAPI (blue) for nuclei. Scale bar indicates $100 \mu \mathrm{m}$ in all images.

concentration dependent manner compared with the BDNF free group. However, significantly longer neurites were observed for the adsorbed BDNF groups compared to that of the soluble BDNF. Even at the lowest surface protein density $\left(0.65 \mathrm{ng} / \mathrm{cm}^{2}\right)$, the mean neurite length was approximately $86 \mu \mathrm{m}$ compared to $73 \mu \mathrm{m}$ for $10 \mathrm{ng} / \mathrm{mL}$ soluble BDNF group. Overall, the longest average neurite length $(141 \mu \mathrm{m})$

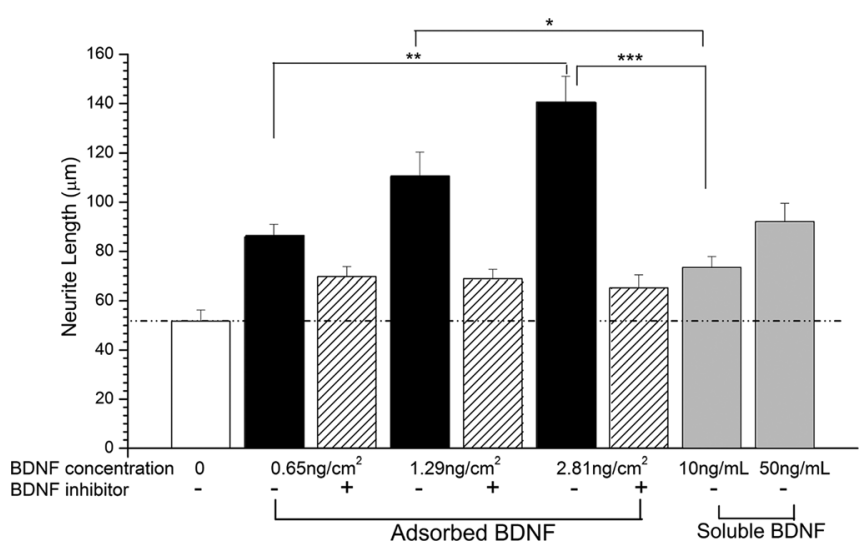

FIG. 7. Neurite length (day 5) of NPCs cultured on P6 surfaces with either the adsorbed or soluble BDNF of different concentrations and their control groups (no BDNF and BDNF inhibited groups). The sample size was $\mathrm{n}=50$ and error bars are shown as standard error of the mean. The no BDNF group showed significant differences to all adsorbed groups and the $50 \mathrm{ng} / \mathrm{mL}$ soluble group ( $<0.001$, Kruskal-Wallis test); the $2.81 \mathrm{ng} / \mathrm{cm}^{2}$ adsorbed BDNF group also had a significant difference to its counterpart where biological activity was blocked $(\mathrm{p}<0.001)$. Significant differences were observed between the adsorbed and soluble BDNF groups. Significance represented at $(* \mathrm{p}<0.05, * * \mathrm{p}<0.01, * * * \mathrm{p}<0.001)$. was observed on $2.81 \mathrm{ng} / \mathrm{cm}^{2}$ adsorbed BDNF (on the P6 terminating layer), which is about 3 times greater than the BDNF negative control and 1.5 times greater than the $50 \mathrm{ng} /$ $\mathrm{mL}$ soluble BDNF group, respectively, for the identical terminating layer. Few cells (individual/clusters) were found on the $\mathrm{H} 7$ with/without adsorbed/soluble BDNF. However, cell clusters found on the $\mathrm{H} 7$ adsorbed/soluble BDNF showed similar levels of neurite outgrowth to $\mathrm{H} 7$ without BDNF.

Quantitative RT-PCR analysis confirmed this synergistic effect between the adhesive promoting P6 surface and neurotrophin support at the level of the induced expression of the receptor message by the exogenously supplied BDNF. The TrkB-FL down-regulation was not observed for the $10 \mathrm{ng} /$ $\mathrm{mL}$ soluble group in our study. In contrast, adsorbed BDNF of different concentrations showed little effect on the TrkB-T1 mRNA after 1 day. A significant down-regulation $(\mathrm{p}<0.05)$ of TrkB-T1 was observed for the $50 \mathrm{ng} / \mathrm{mL}$ soluble BDNF after 1 day of culture. The mRNAs of both TrkB-FL and TrkB-T1 showed fold increases after BDNF was administered for 5 days, which were dose dependent both for the adsorbed and soluble forms. Adsorbed BDNF groups also had a significant effect on the TrkB-T1 mRNA fold increase compared to the BDNF free control groups and showed a 10.6-fold increase for the $2.81 \mathrm{ng} / \mathrm{cm}^{2}$ adsorbed group compared to 3.7 -fold for the $50 \mathrm{ng} / \mathrm{mL}$ soluble group $(\mathrm{p}<0.05)$. In contrast to the TrkB mRNA data, the GAP-43 mRNA was observed to have 2.07 - and 3.03-fold increases $(\mathrm{p}<0.01)$ for the low density/concentration groups, $1.29 \mathrm{ng} /$ $\mathrm{cm}^{2}$ and $10 \mathrm{ng} / \mathrm{ml}$, respectively, after 1 day of culture. However, this returned to a similar level to the no BDNF control groups by day 5 .

\section{DISCUSSION}

The QCM-D in situ characterization of the PEMs revealed, to the first approximation, the mass adsorption upon each PLL and heparin injection. During PBS washing following each deposition process, $\Delta \mathrm{f} / \nu$ changed differentially for the assembled heparin and PLL surfaces. The PBS washing after heparin deposition led to a larger increase of $\Delta \mathrm{f} / \nu$ compared to PLL. The former is due to the removal of loosely attached heparin during washing. We hypothesize that the negligible $\Delta \mathrm{f} / \nu$ change during the PBS washing following the PLL deposition is due to the loose surface chains from the heparin electrolyte rearranging into a dense structure once in contact with the PLL solution and effectively anchoring the PLL chains on the surface of the PEM, ${ }^{43}$ which can be attributed to the higher charge density of heparin compared to PLL. In addition, the frequency dependence of $-\Delta \mathrm{f} / \nu$ (see Fig. 1, inset) indicated a more pronounced viscoelastic behavior of PLL/heparin multilayers as the layer thickness increased, which is also observed in other polyelectrolyte pairs. ${ }^{13,51}$

The surface chemistry and energetics were characterized by water contact angles. The CA values are sensitive to chemical groups within the first $10-20 \AA$ of the outermost surface $^{48}$ and will therefore reflect the chemical nature of the PEM surface. The initial decrease of the CA values (from 
$79^{\circ}$ to $71^{\circ}$ ) after PEI activation indicated the presence of amine moieties that increased the surface hydrophilicity (Fig. 3). ${ }^{52}$ The CA values revealed an alternating step change with heparin surfaces having lower CA values compared to PLL, which can be attributed to hydroxyl moieties within the heparin terminating surface and highlights chemical changes in the terminating layers. ${ }^{49}$ It was previously reported that PLL containing polyelectrolyte pairs had complex island formation during initial deposition cycles, ${ }^{24}$ however, the mechanism for this has not been reported. Based on the AFM results in this study, the PEM surface did not show complex islands and were uniform with nanometer roughness (Fig. 2). Chemical uniformity is critical to clarifying the interpretation of the cellular response to the interfacial features (chemistry, charge, etc.).

The NPCs cultured on the PEMs in the absence of BDNF were studied to assess the cellular response. The significant difference between the PLL terminating surfaces to the heparin surfaces is due to the nonadhesive property of heparin. Figure 4(e) shows significantly different NPCs responses in terms of neurite coverage $(p<0.05)$ between the heparin and PLL terminating layers. The surface chemistry within the first $8 \mathrm{~nm}$ (the approximate thickness of each polyelectrolyte layer) sufficiently influenced neurite sensing and adherence, with greater adhesion and neurite elongation of the PLL terminating layers.

The P6 and $\mathrm{H} 7$ terminating layers were subjected to increasing amounts of BDNF, which adsorbed to their surfaces in a concentration dependent manner (Fig. 5). We proposed that at $p \mathrm{H}=7.4$, the negatively charged heparin surface would impose an attractive Coulombic force to the positively charged BDNF, which explains the generally higher protein adsorption on $\mathrm{H} 7$ compared to P6. However, this effect was not pronounced $(\mathrm{p}<0.1)$ except for the $2 \mu \mathrm{g} / \mathrm{mL}$ BDNF $(\mathrm{p}<0.05)$ concentration, possibly due to significant ionic screening of the protein and the PEM surfaces. ${ }^{53}$

Based on the previous culture results and the BDNF adsorption study, the effect of adsorbed BDNF of different surface densities on the P6 and H7 layers was studied using NPCs and compared to soluble BDNF (Fig. 6). Enhanced neurite outgrowth was observed on P6 surfaces with both adsorbed and soluble BDNF (Fig. 7). The slightly longer neurite length of the BDNF inhibited group compared to the BDNF free group is likely due to incomplete neutralization of BDNF. Since the anti-BDNF antibody takes time to block bioactivity, some BDNF proteins may also bind to TrkB receptors during this time. However, the significant difference $(\mathrm{p}<0.05)$ between adsorbed BDNF and their corresponding inhibited biological controls (except $0.65 \mathrm{ng} / \mathrm{cm}^{2}$ group) did indicate that BDNF maintained its bioactivity after adsorption, highlighting that it was sufficient to further improve neurite outgrowth on the adhesion promoting P6 surfaces. Adsorbed BDNF in combination with the adhesive surface (P6) enhanced the neurite growth compared to the adhesive surface alone or with soluble BDNF. This could provide benefits to the treatment of SCI, since enhanced neurite sprouting and the establishment of new functional connections can repair some lost functions. ${ }^{5,54}$ However, the surface adsorbed or soluble BDNF were not able to stimulate neurite outgrowth from the observed small number of cell clusters on $\mathrm{H} 7$ surfaces, revealing the importance of the adhesive substrate.

Neurotrophic factors stimulate distinct cellular responses depending on their concentration ${ }^{55}$ and time course of treatment. ${ }^{56}$ Acute, prolonged, or gradient changes in the BDNF concentration trigger diverse cellular responses in neurite morphology and ligand/receptor binding efficiency. ${ }^{55,57}$ Since there is no detectable BDNF released from surfaces into the culture media, the stimulatory effects of the BDNF was attributed to the adsorbed form. Here we report that the adsorbed BDNF altered gene expression differently to soluble forms (Fig. 8). The expression of TrkB mRNA is controlled via a protein kinase A (PKA)/cAMP-responsive element-binding protein (CREB)-dependent mechanism. ${ }^{58}$ The prolonged up-regulation of TrkB-FL and TrkB-T1 mRNA until day 5 suggested that this process is on the transcriptional level. Therefore, the up-regulation of TrkB mRNAs for all of the BDNF treated groups reflected the elevated level of intracellular cAMP, which activated TrkB gene transcription. ${ }^{58}$ This is in line with previous studies which have reported that the administration of BDNF to neurons led to a 2-10 fold increase of cAMP. ${ }^{59}$ Even with a BDNF surface density of $2.81 \mathrm{ng} / \mathrm{cm}^{2}$, adsorbed BDNF induced TrkB-FL mRNA expression to a level similar to that found with the highest soluble concentration of BDNF $(50 \mathrm{ng} / \mathrm{mL})$. The slight and significant down-regulations, respectively, of TrkB-FL in $1.29 \mathrm{ng} / \mathrm{cm}^{2}$ adsorbed and $50 \mathrm{ng} /$ $\mathrm{mL}$ soluble BDNF groups after 1 day of BDNF treatment (Fig. 8) is consistent with a previous report that prolonged high concentrations of soluble BDNF $(50 \mathrm{ng} / \mathrm{mL})$ causes down-regulation of TrkB-FL mRNA after 2 days. ${ }^{50}$ While it

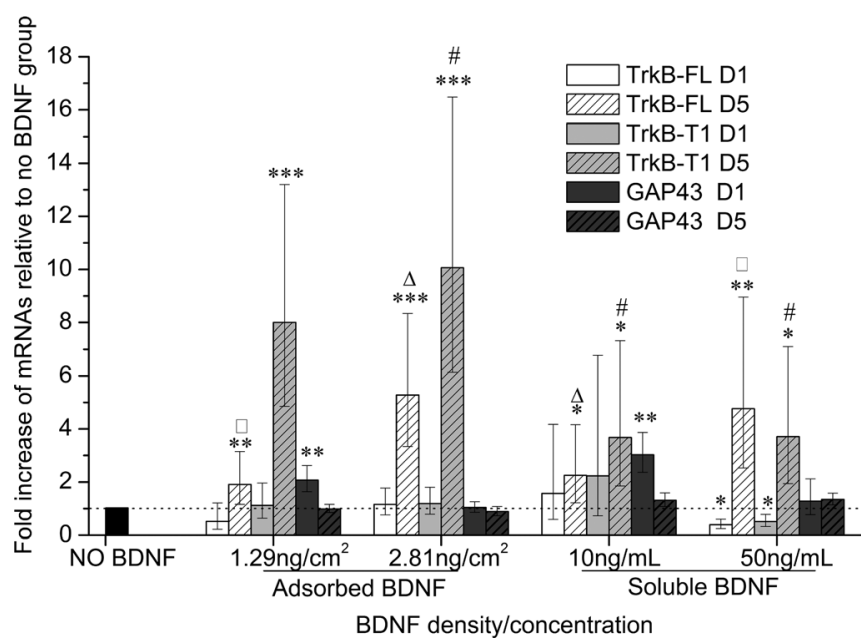

FIG. 8. TrkB-FL, TrkB-T1, and GAP-43 mRNA expression in cells cultured on the P6 terminating layers in the presence of different forms of BDNF. Total RNA was extracted after 1 and 5 days. The sample size was $n=4$, and

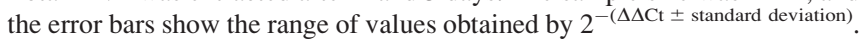
Asterisks indicate significant differences compared to no BDNF group: $* \mathrm{p}<0.05, * * \mathrm{p}<0.01, * * * \mathrm{p}<0.001$ (unpaired t-test with Welch correction). \#, $\Delta$, and $\square$ indicate significant differences $(\mathrm{p}<0.05)$ when comparing adsorbed BDNF groups to soluble groups (one-way ANOVA with Tukey post-test). 
is not possible to quantify the level of the TrkB proteins based on mRNA analysis, it is most likely that elevated cAMP increased the membrane TrkB receptor protein levels. ${ }^{60}$ This is likely to increase the chance of further receptor binding events, along with superior cell-material interfacial interactions. The high TrkB mRNA transcriptional level of adsorbed BDNF compared to soluble forms was possibly due to two reasons: (1) a slower BDNF/TrkB complex internalization and prolonged activation of down-stream signaling pathways including cAMP/PKA (TrkB gene expression) and MAPK/ERK (longer neurite length). ${ }^{61,62}$ Similar influences have shown that prolonged MAPK/ERK activation of PC12 cells occurred and led to differentiation stimulated by immobilized epidermal growth factor; ${ }^{63}$ (2) the high local concentration of BDNF that adsorbed on 2D surfaces polarized signaling from the substrate-cell interface, which could possibly enhance neurite outgrowth ${ }^{64}$ However, it should be acknowledged that covalent immobilization of the BDNF was not adopted in this study, since covalent immobilized BDNF will prevent any internalization of the BDNF/TrkB complex and the subsequent formation of signaling endosomes which cause signaling from different locations and leads to diverse cellular responses. ${ }^{65} \mathrm{We}$ propose that slow internalization and elevated cAMP levels by adsorbed BDNF on the PLL surface would provide a promising solution for transplanted NPCs to overcome the inhibitory environment after SCI, in addition to the enhanced neurite outgrowth, since elevated cAMP is reported to overcome myelin-associated glycoprotein related inhibition. ${ }^{59,66}$ The assessment of cAMP levels will be investigated in future research.

The GAP-43 is an abundant membrane protein concentrated at the neurite growth cone, and is thought to be associated with the neurite outgrowth process, ${ }^{67,68}$ although the precise mechanism is still unclear. During early neuronal development, GAP-43 protein secretion relies on abundant mRNA levels, which then decline during postnatal development. ${ }^{69}$ Given that BDNF was reported to increase the GAP43 mRNA level, ${ }^{37,70}$ we endeavored to determine if an elevated level of GAP-43 mRNA occurred in response to the BDNF treatment, potentially leading to over-expression of GAP-43 and subsequently inducing neurite outgrowth ${ }^{71,72}$ in addition to the ERK signaling pathway that promotes neurite outgrowth. The response of GAP-43 to the BDNF was very different when compared to TrkB mRNA. A 2-3 fold increase was observed only for lower density/concentration groups $\left(1.29 \mathrm{ng} / \mathrm{cm}^{2}\right.$ and $\left.10 \mathrm{ng} / \mathrm{mL}\right)$ of either adsorbed or soluble BDNF, however fold changes dropped back to a similar level to the nontreated group after day 5. A similar shortlasting mRNA increase was reported in a previous in vivo study, ${ }^{70}$ but declined only after 14 days. As revealed by immunostainning, the longest neurites were found on the $2.81 \mathrm{ng} / \mathrm{cm}^{2}$ adsorbed BDNF group, followed by the $1.29 \mathrm{ng} /$ $\mathrm{cm}^{2}$ group, which indicated that the amount of GAP-43 is sufficient for normal neurite outgrowth during early differentiation. However, the elevated mRNA probably did not correlate to a sufficiently high protein level to induce neurite sprouting. ${ }^{71}$

\section{v. CONCLUSION}

The PCL surfaces were successfully biofunctionalized via LbL deposition, with smooth and chemical uniform PEMs deposited. The cellular response of NPCs was significantly different in terms of neurite coverage and length on heparin or PLL terminating layers in the absence of BDNF, with the latter showing remarkable improvement in cell-substrate interaction compared to unmodified PCL. The BDNF alone, in either adsorbed or soluble form on heparin terminating layers, was insufficient to stimulate neurite outgrowth, while the combined effect of an adhesive interface and presentation of BDNF revealed pronounced stimulatory effects. The overall density/concentration dependence on neurite length was observed for the adsorbed and soluble BDNF stimulation, while the adsorbed BDNF enhanced the outgrowth compared to the soluble form. This enhancement was attributed to sustained activation from the BDNF/TrkB binding, which led to elevated TrkB-FL mRNA and possibly cAMP/ CREB levels rather than GAP-43 induced neurite outgrowth. This work reveals the importance of combined cues of celladhesive interface and neurotrophin support during early development of NPCs in vitro, along with the potential application of bio-functionalized PEMs with adsorbed BDNF to provide well-controlled local accessibility of the neurotrophic factor with sustained signal activation in vivo for SCI treatment.

\section{ACKNOWLEDGMENTS}

This work is supported by grants from the Australian Research Council (Grant No. DP0985433), the Baker Foundation, Bellberry Ltd, and the National Health and Medical Research Council of Australia.

\section{APPENDIX}
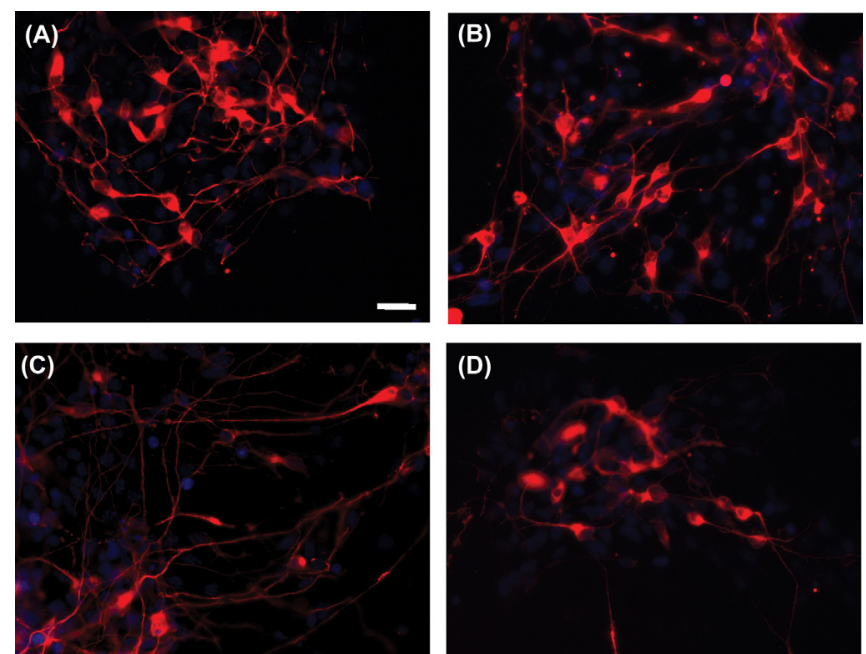

FIg. 9. (Color online) Chosen high resolution images from Fig. 6. Images correspond to (a) No BDNF, (b) $50 \mathrm{ng} / \mathrm{mL}$ soluble BDNF, (c) $2.81 \mathrm{ng} / \mathrm{cm}^{2}$ adsorbed BDNF, and (d) $2.81 \mathrm{ng} / \mathrm{cm}^{2} \mathrm{BDNF}$ inhibited groups. 
${ }^{1}$ M. T. Fitch and J. Silver, Exp. Neurol. 209, 294 (2008).

${ }^{2}$ V. Kottis, P. Thibault, D. Mikol, Z.-C. Xiao, R. Zhang, P. Dergham, and P. E. Braun, J. Neurochem. 82, 1566 (2002).

${ }^{3}$ J. W. Fawcett, Spinal Cord 36, 811 (1998).

${ }^{4}$ S. M. Willerth and S. E. Sakiyama-Elbert, Adv. Drug Delivery Rev. 60, 263 (2008).

${ }^{5}$ F. M. Bareyre, J. Neurol. Sci. 265, 63 (2008).

${ }^{6}$ H. Tabesh, G. Amoabediny, N. S. Nik, M. Heydari, M. Yosefifard, S. O. R. Siadat, and K. Mottaghy, Neurochem. Int. 54, 73 (2009).

${ }^{7}$ D. R. Nisbet, S. Pattanawong, N. E. Ritchie, W. Shen, D. I. Finkelstein, M. K. Horne, and J. S. Forsythe, J. Neural Eng. 4, 35 (2007).

${ }^{8}$ D. R. Nisbet, K. E. Crompton, M. K. Horne, D. I. Finkelstein, and J. S. Forsythe, J. Biomed. Mater. Res., Part B: Appl. Biomater. 87B, 251 (2008).

${ }^{9}$ S. Woerly, E. Pinet, L. de Robertis, D. Van Diep, and M. Bousmina, Biomaterials 22, 1095 (2001).

${ }^{10}$ D. R. Nisbet, L. M. Y. Yu, T. Zahir, J. S. Forsythe, and M. S. Shoichet, J. Biomater. Sci., Polym. Ed. 19, 623 (2008).

${ }^{11}$ H. Nomura, C. H. Tator, and M. S. Shoichet, J. Neurotrauma 23, 496 (2006).

${ }^{12}$ C. Boura, P. Menu, E. Payan, C. Picart, J. C. Voegel, S. Muller, and J. F. Stoltz, Biomaterials 24, 3521 (2003).

${ }^{13}$ L. Richert, P. Lavalle, E. Payan, X. Z. Shu, G. D. Prestwich, J. F. Stoltz, P. Schaaf, J. C. Voegel, and C. Picart, Langmuir 20, 448 (2004).

${ }^{14}$ Y. Gong, Y. Zhu, Y. Liu, Z. Ma, C. Gao, and J. Shen, Acta Biomater. 3, 677 (2007).

${ }^{15}$ S. Ahmed, B. A. Reynolds, and S. Weiss, J. Neurosci. 15, 5765 (1995).

${ }^{16}$ S. Mehrotra, D. Lynam, R. Maloney, K. M. Pawelec, M. H. Tuszynski, I. Lee, C. Chan, and J. Sakamoto, Adv. Funct. Mater. 20, 247.

${ }^{17}$ S. S. Shiratori and M. F. Rubner, Macromolecules 33, 4213 (2000).

${ }^{18}$ S. Boddohi, C. E. Killingsworth, and M. J. Kipper, Biomacromolecules 9 , 2021 (2008)

${ }^{19}$ L. Richert, A. J. Engler, D. E. Discher, and C. Picart, Biomacromolecules 5, 1908 (2004).

${ }^{20}$ C. B. Bucur, Z. Sui, and J. B. Schlenoff, J. Am. Chem. Soc. 128, 13690 (2006).

${ }^{21}$ B. Schoeler, E. Poptoshev, and F. Caruso, Macromolecules 36, 5258 (2003).

${ }^{22}$ P. Bertrand, A. Jonas, A. Laschewsky, and R. Legras, Macromol. Rapid Commun. 21, 319 (2000).

${ }^{23}$ J. Almodovar, S. Bacon, J. Gogolski, J. D. Kisiday, and M. J. Kipper, Biomacromolecules 11, 2629 (2010).

${ }^{24}$ C. Picart, P. Lavalle, P. Hubert, F. J. G. Cuisinier, G. Decher, P. Schaaf, and J. C. Voegel, Langmuir 17, 7414 (2001).

${ }^{25}$ M. Houska, E. Brynda, and K. Bohat, J. Colloid Interface Sci. 273, 140 (2004).

${ }^{26}$ H. Min, E. S. Eric, T. Charlotte, T. Jasmine, and R. H. Vincent, Tissue Eng. 6, 585 (2000).

${ }^{27}$ D. R. Nisbet, D. Moses, T. R. Gengenbach, J. S. Forsythe, D. I. Finkelstein, and M. K. Horne, J. Biomed. Mater. Res. Part A 89A, 24 (2009).

${ }^{28}$ E. Young, Thromb. Res. 122, 743 (2008).

${ }^{29}$ D. J. Tyrrell, A. P. Horne, K. R. Holme, J. M. H. Preuss, C. P. Page, M. W. A. F. M. J. Thomas August, and T. C. Joseph, "Heparin in Inflammation: Potential Therapeutic Applications beyond Anticoagulation," in Advances in Pharmacology (Academic, New York, 1999), p. 151.

${ }^{30} \mathrm{~J}$. Fu, J. Ji, W. Yuan, and J. Shen, Biomaterials 26, 6684 (2005).

${ }^{31}$ L. D. Thompson, M. W. Pantoliano, and B. A. Springer, Biochemistry 33, 3831 (1994).

${ }^{32}$ J. J. Yoon, H. J. Chung, H. J. Lee, and T. G. Park, J. Biomed. Mater. Res. Part A (2006).

${ }^{33}$ M. Philippe, M. M. Claudia, R. W. Scott, P. B. Richard, and B. M. Bartlett, Eur. J. Neurosci. 10, 607 (1998).

${ }^{34}$ A. G. Rabchevsky, I. Fugaccia, A. F. Turner, D. A. Blades, M. P. Mattson, and S. W. Scheff, Exp. Neurol. 164, 280 (2000).

${ }^{35}$ X.-Y. Song, F. Li, F.-H. Zhang, J.-H. Zhong, and X.-F. Zhou, PLoS One 3, e1707 (2008).

${ }^{36}$ J. F. Poduslo and G. L. Curran, Brain Res. Mol. Brain Res. 36, 280 (1996).

${ }^{37}$ N. R. Kobayashi, D.-P. Fan, K. M. Giehl, A. M. Bedard, S. J. Wiegand, and W. Tetzlaff, J. Neurosci. 17, 9583 (1997).
${ }^{38}$ M. Stroh, W. R. Zipfel, R. M. Williams, S. C. Ma, W. W. Webb, and W. M. Saltzman, Nature Mater. 3, 489 (2004).

${ }^{39}$ S. Biffo, N. Offenhauser, B. D. Carter, and Y. A. Barde, Development 121, 2461 (1995).

${ }^{40}$ L. Richert, P. Lavalle, D. Vautier, B. Senger, J. F. Stoltz, P. Schaaf, J. C. Voegel, and C. Picart, Biomacromolecules 3, 1170 (2002).

${ }^{41}$ D. R. Nisbet, A. E. Rodda, M. K. Horne, J. S. Forsythe, and D. I. Finkelstein, Biomaterials 30, 4573 (2009).

${ }^{42}$ M. V. Voinova, M. Jonson, and B. Kasemo, Biosens. Bioelectron. 17, 835 (2002).

${ }^{43}$ D. Yoo, S. S. Shiratori, and M. F. Rubner, Macromolecules 31, 4309 (1998).

${ }^{44}$ I. Husson, C.-M. Rangon, V. Lelievre, A.-P. Bemelmans, P. Sachs, J. Mallet, B. E. Kosofsky, and P. Gressens, Cereb. Cortex 15, 250 (2005).

${ }^{45}$ J. Bilsland, M. Rigby, L. Young, and S. Harper, J. Neurosci. Methods 92, 75 (1999).

${ }^{46}$ E. Meijering, M. Jacob, J. C. F. Sarria, P. Steiner, H. Hirling, and M. Unser, Cytometry, Part A 58A, 167 (2004).

${ }^{47}$ M. V. Voinova, M. Rodahl, M. Jonson, and B. Kasemo, Phys. Scr. 59, 391 (1999).

${ }^{48}$ W. A. Zisman, "Relation of equilibrium contact angle to liquid and solid constitution," in Contact Angle, Wettability and Adhesion, Advances in Chemistry Series 43, (American Chemical Society, 1964, Washington, DC).

${ }^{49}$ M. Bibel, J. Richter, E. Lacroix, and Y.-A. Barde, Nat. Protoc. 2, 1034 (2007).

${ }^{50}$ L. Frank, R. Ventimiglia, K. Anderson, R. M. Lindsay, and J. S. Rudge, Eur. J. Neurosci. 8, 1220 (1996).

${ }^{51}$ C. Picart, J. Mutterer, L. Richert, Y. Luo, G. D. Prestwich, P. Schaaf, J. C. Voegel, and P. Lavalle, Proc. Natl. Acad. Sci. U.S.A. 99, 12531 (2002).

${ }^{52}$ Y. Zhu, C. Gao, X. Liu, and J. Shen, Biomacromolecules 3, 1312 (2002).

${ }^{53}$ M. Bellion, L. Santen, H. Mantz, H. Hahl, A. Quinn, A. Nagel, C. Gilow, C. Weitenberg, Y. Schmitt, and K. Jacobs, J. Phys.: Condens. Matter 20, 404226 (2008).

${ }^{54}$ I. C. Maier and M. E. Schwab, Philos. Trans. R. Soc. London, Ser. B 361, 1611 (2006).

${ }^{55}$ Y. Ji, Y. Lu, F. Yang, W. Shen, T. T.-T. Tang, L. Feng, S. Duan, and B. Lu, Nat. Neurosci. 13, 302.

${ }^{56}$ R. J. Tolwani, P. S. Buckmaster, S. Varma, J. M. Cosgaya, Y. Wu, C. Suri, and E. M. Shooter, Neuroscience 114, 795 (2002).

${ }^{57}$ B. D. Carter, U. Zirrgiebel, and Y.-A. Barde, J. Biol. Chem. 270, 21751 (1995).

${ }^{58}$ R. Deogracias, G. Espliguero, T. Iglesias, and A. Rodriguez-Pena, Mol. Cell. Neurosci. 26, 470 (2004).

${ }^{59}$ D. Cai, Y. Shen, M. De Bellard, S. Tang, and M. T. Filbin, Neuron 22, 89 (1999).

${ }^{60}$ A. Meyer-Franke, G. A. Wilkinson, A. Kruttgen, M. Hu, E. Munro, M. G. Hanson, L. F. Reichardt, and B. A. Barres, Neuron 21, 681 (1998).

${ }^{61}$ J. K. Atwal, B. Massie, F. D. Miller, and D. R. Kaplan, Neuron 27, 265 (2000).

${ }^{62}$ J. C. Perron and J. L. Bixby, Mol. Cell. Neurosci. 13, 362 (1999).

${ }^{63}$ Y. Ito, G. Chen, Y. Imanishi, T. Morooka, E. Nishida, Y. Okabayashi, and M. Kasuga, J. Biochem. (Tokyo) 129, 733 (2001).

${ }^{64} \mathrm{Q}$. Li and Y. Chau, J. Biomed. Mater. Res. Part A 94A, 688 (2010).

${ }^{65}$ Y.-Z. Zhang, D. B. Moheban, B. R. Conway, A. Bhattacharyya, and R. A. Segal, J. Neurosci. 20, 5671 (2000).

${ }^{66}$ Y. Gao, E. Nikulina, W. Mellado, and M. T. Filbin, J. Neurosci. 23, 11770 (2003).

${ }^{67}$ L. Aigner, S. Arber, J. P. Kapfhammer, T. Laux, C. Schneider, F. Botteri, H.-R. Brenner, and P. Caroni, Cell 83, 269 (1995).

${ }^{68}$ K. F. Meiri, J. L. Saffell, F. S. Walsh, and P. Doherty, J. Neurosci. 18, 10429 (1998).

${ }^{69}$ R. D. Jacobson, I. Virag, and J. H. Skene, J. Neurosci. 6, 1843 (1986).

${ }^{70}$ A. E. Fournier, J. Beer, C. O. Arregui, C. Essagian, A. J. Aguayo, and L. McKerracher, J. Neurosci. Res. 47, 561 (1997).

${ }^{71}$ A. Buffo, A. J. D. G. Holtmaat, T. Savio, J. S. Verbeek, J. Oberdick, A. B. Oestreicher, W. H. Gispen, J. Verhaagen, F. Rossi, and P. Strata, J. Neurosci. 17, 8778 (1997).

${ }^{72}$ P. Caroni, L. Aigner, and C. Schneider, J. Cell Biol. 136, 679 (1997). 